\title{
Simulation of Soft Switched Pwm Zvs Full Bridge Converter
}

\author{
Deepak Kumar Nayak and S.Rama Reddy
}

\begin{abstract}
This paper deals with the analysis and simulation of soft switched PWM ZVS full bridge DC to DC converter. The $48 \mathrm{~V}$ DC is efficiently reduced to $12 \mathrm{~V}$ DC using a DC to DC converter. This converter has advantages like reduced switching losses, stresses and EMI. Input DC is converted into high frequency $\mathrm{AC}$ and it is stepped down to $12 \mathrm{~V}$ level. Latter it is rectified using a full wave rectifier. The simulation results are compared with the analytical results.
\end{abstract}

Index Terms-DC-DC converter, full bridge converter, soft -switching, zero voltage switching (ZVS)

\section{INTRODUCTION}

The continuing success of square-wave PWM topology in switching converters can be attributed to its ease of operation. The harmonics can easily be eliminated by power filter and it has a capability in allowing continuous and linear control of the frequency and fundamental component of the output voltage. But with the demands for higher power densities, the switching frequencies are approaching $1 \mathrm{MHz}$ range. At these frequencies, square wave converters' switching losses become very high leading to excessive heat dissipation. Even if the increased switching frequency does not cause unacceptable switching losses, the oscillations caused by converter parasitic elements may cause high current and voltage stresses, which are almost unpredictable, depending on circuit layout. Suitable snubber circuits must therefore be adopted, which affect power density and converter reliability. The zero-voltage transition approach, as well as the active-clamp snubber approach, leads to zero-voltage switching of the transistors and zero-current switching of the diodes. These approaches have been successful in substantially improving the efficiencies of transformer-isolated converters.

The Zero-voltage switching (ZVS) phase shift modulated full bridge (PSM-FB) DC/DC converter with MOSFET switches has been proposed in [1],[2]. Low component count and zero full load switching losses enable this topology to achieve low cost, high power density, high efficiency, and low EMI, so for medium to high power DC/DC applications it is a good choice.

The phase-shifted PWM full bridge (FB) converter incorporates the leakage inductance of the transformer to achieve zero-voltage switching, but only achieves it near the full load condition.
Several new techniques for high frequency DC-DC conversion are there to reduce component stresses and switching losses while achieving high power density and improved performance. Among them, the full-bridge (FB) zero-voltage-switched (ZVS) converter is one of the most attractive techniques which is shown in Fig. 1. It is the most widely used soft-switched circuit in high-power applications, [1]-[3]. This constant-frequency converter employs phase-shift (PS) control and features ZVS of the primary switches with relatively small circulating energy. However, full ZVS operation can only be achieved with a limited load and input-voltage range, unless a relatively large inductance is provided in series with the primary winding of the transformer either by an increased leakage inductance of the transformer and/or by an additional external inductor. This increased inductance has a detrimental effect on the performance of the converter since it causes an increased loss of the duty cycle on the secondary side, as well as severe voltage ringing across the secondary-side output rectifiers due to the resonance between the inductance and the junction capacitance of the rectifier. The secondary-side ringing can be suppressed by an active snubber described in [2]. For implementations with an external primary inductor, the ringing can also be effectively controlled by employing primary-side clamp diodes D and D1 shown in Fig. 1, as proposed in [2]. While the snubber approaches in [1] and [2] offer practical and efficient solutions to the secondary-side ringing problem, they do not offer any improvement of the secondary-side duty-cycle loss.

Several techniques have been proposed to extend the ZVS range of FB ZVS converters without the loss of duty cycle and secondary-side ringing [4]-[7]. Generally, these circuits utilize energy stored in the inductive components of an auxiliary circuit to achieve ZVS for all primary switches in an extended load and input voltage range. Ideally, the auxiliary circuit needs to provide very little energy, if any, at full load because the full-load current stores enough energy in the converter's inductive components to achieve complete ZVS for all switches. As the load current decreases, the energy provided by the auxiliary circuit must increase to maintain ZVS, with the maximum energy required at no load. The energy stored for ZVS is independent of load as described in [4] and [5]. Adaptive energy storage in the auxiliary circuit has been introduced in [6] and [7]. However, these converters have to use large inductors so, high circulating energy that is needed $^{1}$ to achieve no-load ZVS and that is due to a relatively large inductor employed to assist ZVS. 


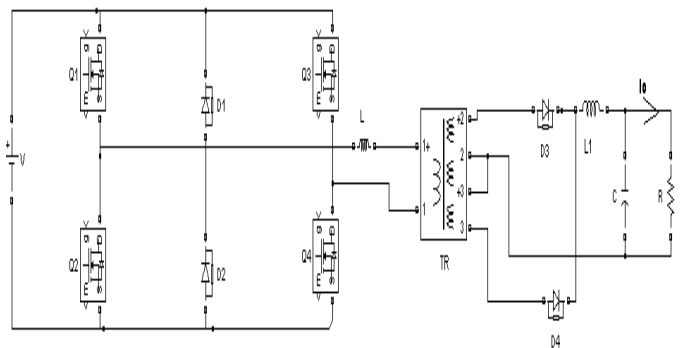

Fig.1 PWM Full Bridge Converter

In this paper, a FB ZVS converter with adaptive energy storage that offers ZVS of the primary switches over a wide load range with greatly reduced no-load circulating energy and with significantly reduced secondary-side duty cycle loss is introduced with PWM control. ZVS full bridge DC to DC converter with ZVS over the entire range is given by[8].High power density multikilowatt DC to DC converter with galvanic isolation is given by [9]. The literature [1] to [9] does not deal with the modeling and simulation of closed loop controlled PWM ZVS full bridge converter. This works aims to develop circuit model for ZVS full bridge converter.

\section{PWM Zvs FB CONVERTER WITH AUXILIARY TRANSFORMER}

Fig. 2 shows the FB ZVS converter circuit diagram that provides ZVS for the bridge switches over a wide range of load current. It employs low-power auxiliary transformer TRA to extend the ZVS range. The primary of auxiliary transformer TRA is connected to the center tap of power transformer TR and the ground through blocking capacitor $\mathrm{C} 1$, whereas its secondary is connected in series with the primary winding of power transformer TR and inductor Lp .Auxiliary transformer TRA is only used to adaptively store a relatively small amount of energy into primary inductor that is required for ZVS. Finally, two diodes are connected from the node connecting the primary of the power transformer and the secondary of the auxiliary transformer to the positive and negative (ground) rails of the bridge to provide a path for the current through primary inductor, $\mathrm{Lp}$ which is used to store ZVS energy.

When the load voltage is regulated, as the load current and/or input voltage decreases, the duty cycle of each PWM switch, i.e., switches Q3 and Q4 decreases so that the volt-second product on the windings of power transformer TR also decreases. At the same time, the volt-second product on the windings of auxiliary transformer TRA increases, which proportionally increases the energy stored in the primary inductor. Due to the adaptive nature of the energy available for ZVS stored in the primary inductor, which increases as the load current and/or input voltage decreases, the proposed circuit can achieve ZVS in a very wide range of load current, including no load, with minimal circulating energy.

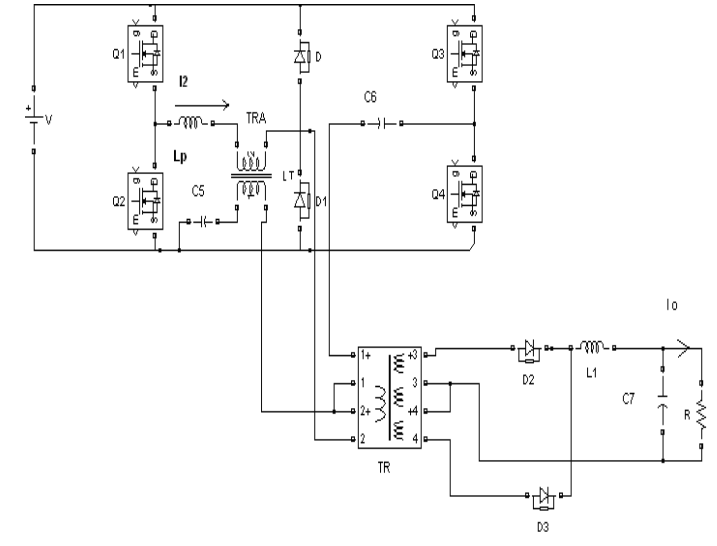

Fig.2 FB ZVS converter with auxiliary transformer

\section{Technical Specifications of Fig.2:}

$\mathrm{DC} \quad$ input $\quad$ voltage $=48 \mathrm{~V}, \mathrm{Lp}=84 \mu \mathrm{F}, \quad \mathrm{R}=10 \Omega$, $\mathrm{L} 1=0.07 \mu \mathrm{H}, \mathrm{C} 7=1200 \mu \mathrm{F}, \mathrm{C} 5=0.5 \mu \mathrm{F}, \mathrm{C} 6=12 \mu \mathrm{F}$,

Operating frequency $=20 \mathrm{KHz}$.

In the modified circuit, since the ZVS energy stored in the primary inductor is dependent on its inductance value and the volt-second product of the secondary of auxiliary transformer TRA, the size of the primary inductor can be minimized by properly selecting the turns ratio of auxiliary transformer TRA. As a result, the size of the primary inductor is very much reduced compared to that of the conventional PS FB converter shown in Fig.1. In addition, since the auxiliary transformer does not need to store energy, its size can be small. Finally, because the energy used to create the ZVS condition at light loads is not stored in the leakage inductances of transformer TR, the transformer's leakage inductances can also be minimized. As a result of the reduced total primary inductance, i.e., the inductance of the primary inductor used for ZVS energy storage and the leakage inductance of the power transformer, the proposed converter exhibits a relatively small duty-cycle loss, which minimizes both the conduction loss of the primary switches and the voltage stress on the components on the secondary side of the transformer, which improves the conversion efficiency. Moreover, because of the reduced total primary inductance, the secondary- side parasitic ringing is also reduced and is effectively controlled by primary side diodes D and D1.

\section{OPERATIONAL PRINCIPLE}

The circuit diagram of the modified converter is shown in Fig.2.The primary side consists of four switches, two diodes, one inductor, and one capacitor. It employs low power auxiliary transformer TRA to extend the ZVS range. At light loads energy used to create ZVS is not stored in the leakage inductance of the transformer TR .So, The transformer's leakage inductance can be minimized. Energy stored in primary inductor depends on volt-second product of the secondary of auxiliary transformer TRA and inductance value. So by selecting proper turn ratio of auxiliary transformer TRA, the size of the primary inductor can be minimized. Auxiliary transformer is not used to store energy. So, its size can be small. Several assumptions are made as follows. 
1) Capacitance of capacitor $\mathrm{C} 5$ is large enough so that the capacitor can be modeled as a constant voltage source.

2) The inductance of output filter L1 is large enough so that during a switching cycle the output filter can be modeled as a constant current source.

3) The leakage inductance of auxiliary transformer TRA and the magnetizing inductances of both transformers are neglected.

4) The resistance of each conducting switch is zero, whereas the resistance of each non-conducting switch is infinite.

5) Current through primary side of auxiliary transformer TRA is zero.
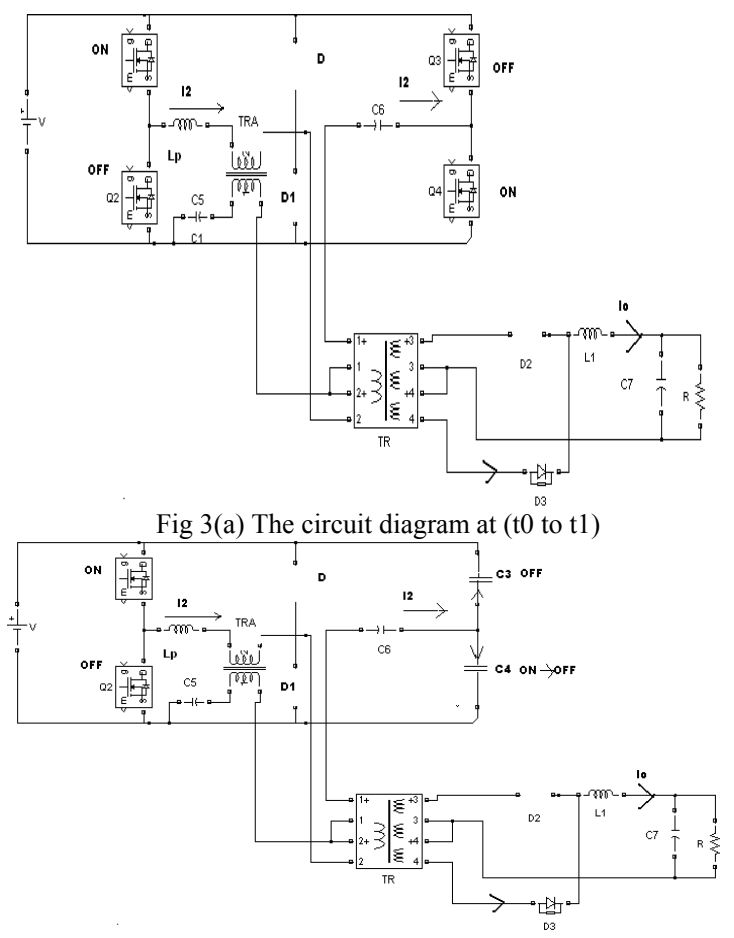

Fig 3(b) The circuit diagram at (t1 to t2)

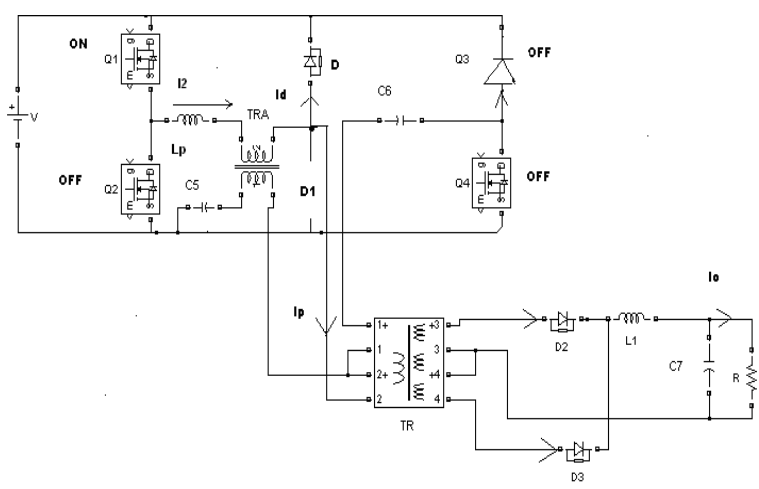

Fig 3(c) The circuit diagram at (t2 to t3)

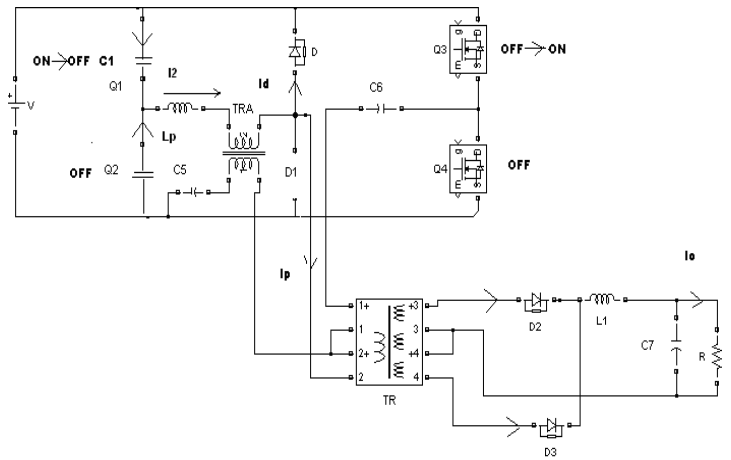

Fig 3(d) The circuit diagram at ( $\mathrm{t}_{3}$ to $\left.\mathrm{t}_{4}\right)$

As shown in Fig,3(a), at $\mathrm{t}=\mathrm{t}_{0}$, load current flows through rectifier D3 and the lower secondary of power transformer TR. when diagonal switches Q1 and Q2 are conducting. Since during this topological stage diodes D and D1 are reverse biased, the reflected primary current is flowing through closed switch Q1, primary inductor Lp winding $\mathrm{N}_{2}$ of auxiliary transformer TRA, primary winding $\mathrm{N}_{\mathrm{p}}$ of transformer TR, and closed switch Q4. Since the impendence of the primary inductor $\mathrm{Lp}$ and winding $\mathrm{N}_{2}$ of auxiliary transformer TRA are very small compare to primary referred filter inductor $\mathrm{L}_{\mathrm{o}}$. Let $\mathrm{V}_{\mathrm{o}}$ ' is the primary referred output DC voltage.

Slope of the primary current is given by $\left(\mathrm{V}_{\mathrm{DC}}-\mathrm{V}_{\mathrm{o}}{ }^{\prime}\right) / \mathrm{L}_{\mathrm{o}}{ }^{\prime}$. Centre tap of primary voltage is given by $V_{P} / 2=V / 2$ because impendence of primary inductor Lp and winding $\mathrm{N}_{2}$ of TRA are small. At $\mathrm{t}=\mathrm{t}_{1}$ as shown in Fig. 3(b), switch Q4 is turned off, primary current starts charging output capacitance $\mathrm{C} 4$ of switch Q4 and discharges output capacitance C3 of switch Q3. The total required energy to charge C4and discharge C3 is provided not only from the stored energy of $\mathrm{Lp}$, but also from the stored energy of the output filter inductor. Since the stored energy in the output filter inductor is significantly larger than the required energy to charge $\mathrm{C} 4$ and discharge C3, these capacitors are assumed to be charged and discharged linearly. Voltage across switch $\mathrm{Q}_{4}$ increases towards $\mathrm{V}$ and voltage across switch $\mathrm{Q}_{3}$ decreases towards zero. Primary winding voltage of auxiliary transformer increases from zero to $\mathrm{V} / 2$ and secondary winding of auxiliary transformer increases from zero to $V / 2$ ni where ni is the auxiliary transformer turn ratio. Diode $\mathrm{D}$ starts conducting because of increasing secondary voltage of auxiliary transformer. After voltage across Q3 reaches zero diode across Q3 starts conducting at $\mathrm{t}=\mathrm{t}_{2}$ as shown in Fig. 4(c).

When the voltage across switch Q3 becomes zero, voltage across the power transformer also becomes zero since the primary of the transformer is shorted by the simultaneous conduction of the body diode of Q3 and diode D. As a result, the secondary windings are also shorted so that rectifiers D2 and D3 can conduct the load current simultaneously. However, because of the leakage inductance of transformer TR, load current Io is still carried by the lower secondary through rectifier D3 since no voltage is available to commutate the current from the lower secondary and D3 to the upper secondary and D2 if ideal components are assumed. With real components this commutation voltage exists, but is 
too small to commutate a significant amount of current from the lower to the upper secondary so that even with real components the majority of the current is still found in the lower secondary and its corresponding rectifier D3. So, during this stage when switches Q1 and Q3 are conducting, primary current stays nearly unchanged.

During this stage, diode $\mathrm{D}$ is conducting and voltage $\mathrm{V}_{2}$ is applied directly across primary inductor $\mathrm{Lp}$, Which increases current $\mathrm{I} 2$ until $\mathrm{Q} 1$ is turned off at $\mathrm{t}=\mathrm{t}_{3}$ as shown in Fig 4(d).Current $\mathrm{I} 2(\mathrm{t})$ in the interval of $\mathrm{t}_{2}$ to $\mathrm{t}_{3}$ can be given as $\mathrm{I} 2(\mathrm{t})=\mathrm{Ip}+\mathrm{Id}(\mathrm{t})=\mathrm{I}_{\mathrm{o}} / \mathrm{n}+\left\{\mathrm{V} / 2\right.$ niLp $\left.\left(\mathrm{t}-\mathrm{t}_{2}\right)\right\}$

Where $\operatorname{Id}(\mathrm{t})$ is the current across diode $\mathrm{D}$.

$\mathrm{n}=$ turn ratio of power transformer.

During this stage, the voltage across switch Q3 is kept zero due to D. So switch $\mathrm{Q}_{3}$ is turned on with ZVS. After Q1 is turned off ,current $\mathrm{I} 2$ begins charging output capacitance $\mathrm{C} 1$ of switch Q1 and discharging capacitance C2 of switch $\mathrm{Q} 2$. The total energy required to charge $\mathrm{C} 1$ and discharge $\mathrm{C} 2$ is supplied from the stored energy in the primary inductor Lp. To achieve ZVS energy stored in the primary inductor $\left(\mathrm{E}_{\mathrm{LP}}\right)$ must be higher than total energy required to charge $\mathrm{C} 1$ and discharge C2

Where $\mathrm{C} 1=\mathrm{C} 2=\mathrm{C}$

$$
E_{L P} \geq C V^{2}
$$

Using equation (1)

$$
E_{L P}=\frac{1}{2} L_{P}\left(\frac{I o}{n}+\frac{V(1-D)}{4 n i L_{p} f_{S}}\right)^{2}
$$

Where $f_{s}$ is the switching frequency.

From equation (2) and (3)

$$
L_{P}\left(\frac{I o}{n}+\frac{V(1-D)}{4 n i L_{P} f_{S}}\right) \geq 2 C V^{2}
$$

Where $\mathrm{D}$ is the duty cycle of the converter.

Then primary current continue to flow through antiparallel diode of switch Q2 so that Q2 can be turned on with ZVS.

In this stage Voltage $\mathrm{V}_{\mathrm{s} 1}$ across switch Q1, which is in opposition to voltage $V_{2}$, is increasing and current Id starts decreasing. When Id becomes zero Diode D stops conducting so that primary current starts decreasing. Load current Io also begins to commutate from the lower secondary and D3 to upper secondary and D2. When the commutation of the load current from the lower to upper secondary is completed, the primary current commutation from the positive to negative direction is also finished.

The circuit stays with diagonal switches Q2 and Q3 turned on until the switch Q3 is turned off. Second half of the switching period is exactly the same as the first half of the switching period.

The circuit stays with diagonal switches Q2 and Q3 turned on until the switch Q3 is turned off. Second half of the switching period is exactly the same as the first half of the switching period.

\section{Simulation Results}

The ZVS DC to DC converter is simulated using matlab simulink and the results are presented here.

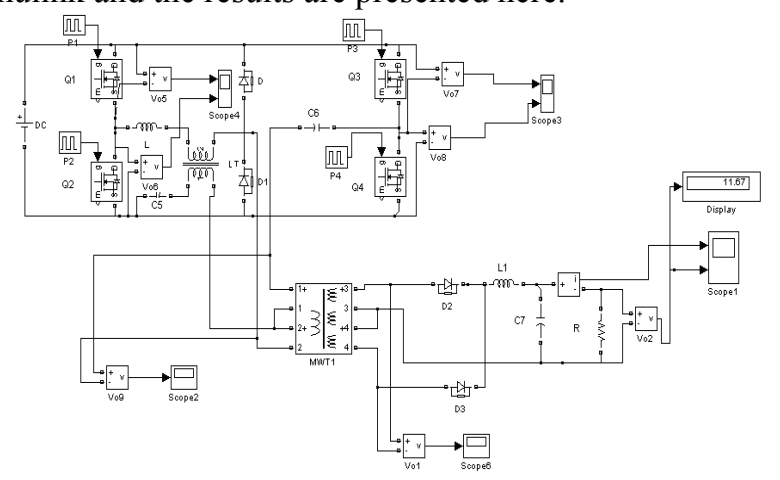

Fig.4 Simulink Model Of ZVS DC to DC converter

Simulink model of DC to DC converter is shown in Fig 4. Driving pulses are shown in Fig. 5.

DC input voltage is shown in Fig 6.Output voltage across Q1 \& Q2 is shown in Fig 7.Voltage across Q3 \& Q4 are shown in Fig 8. .Secondary voltage is shown in Fig 9. DC output current and voltage are shown in Fig. 10. DC output voltage is $12 \mathrm{~V}$ and the current is $1 \mathrm{~A}$. It can be seen that the $\mathrm{DC}$ output is free from ripple

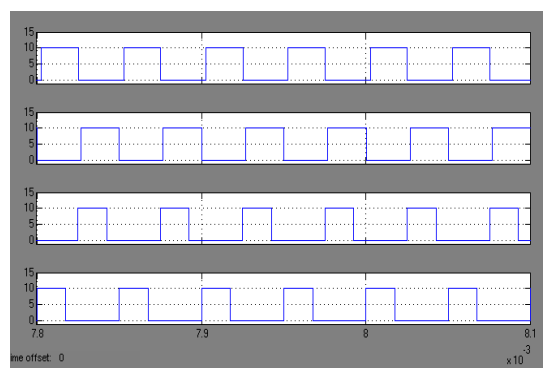

Fig.5 Driving Pulses

For constant-frequency, variable duty cycle control of the proposed converter, switches Q1 and Q2 always operate with approximately $50 \%$ duty cycle, whereas switches Q3 and Q4 have a duty cycle in the range from $0 \%$ to $50 \%$ as shown in Fig 5.

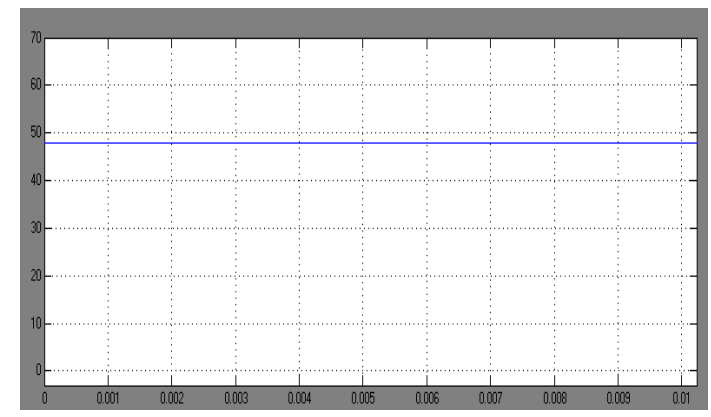

Fig.6 DC Input Voltage 


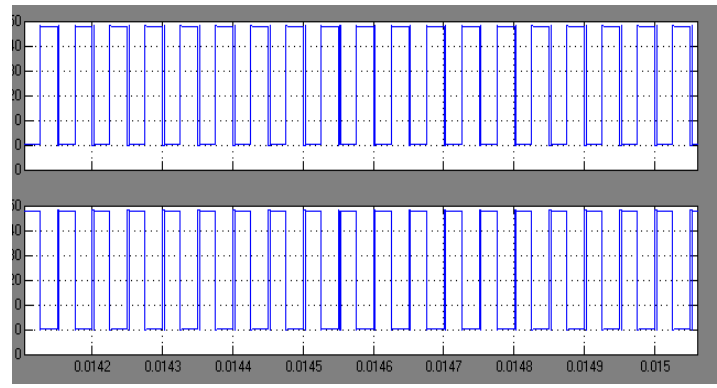

Fig.7 Output Voltage across Q1 and Q2

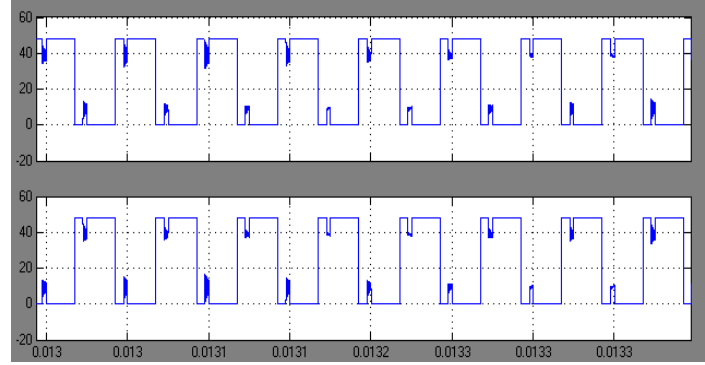

Fig.8 Output voltage across Q3 and Q4

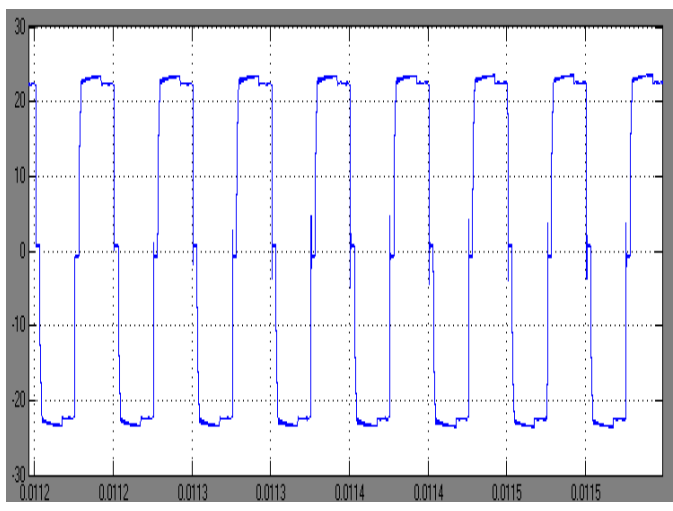

Fig. 9 Voltage across the secondary

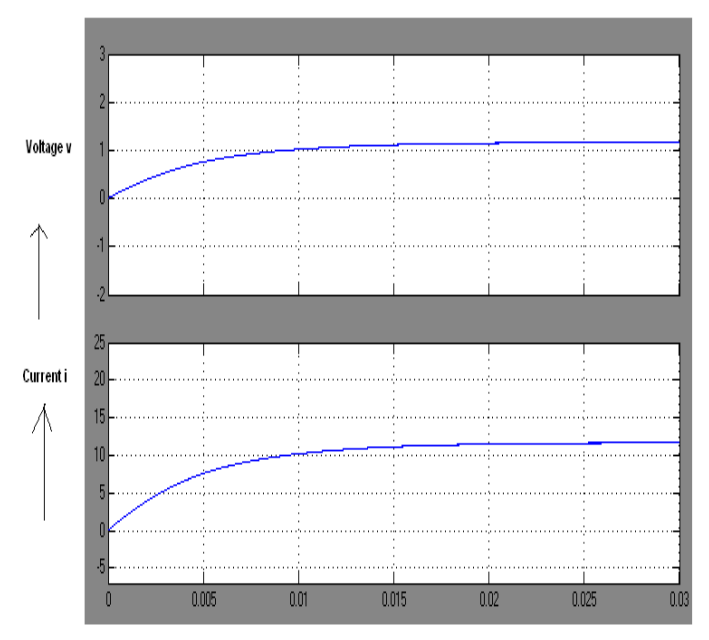

Timein set

Fig.10 DC output current and voltage

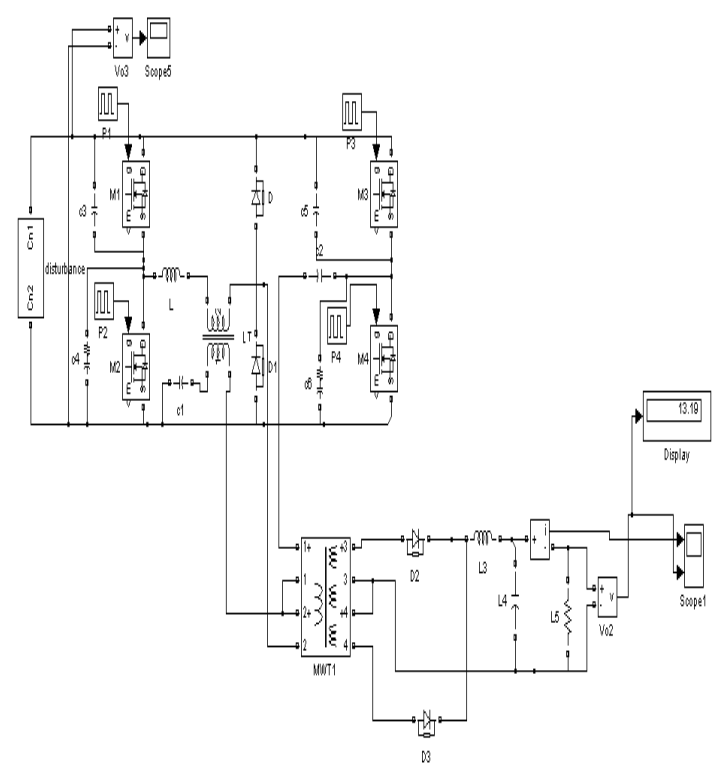

Fig.11 Open loop system

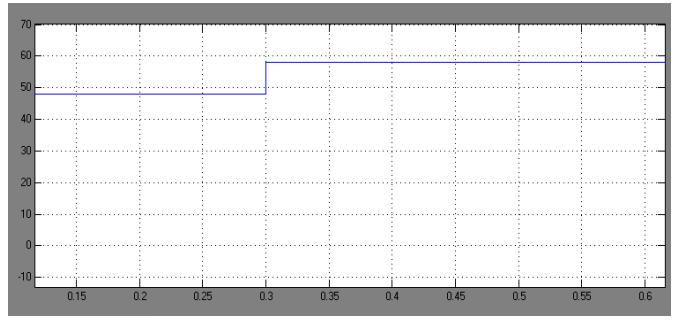

Fig.12 Dc input voltage with disturbance

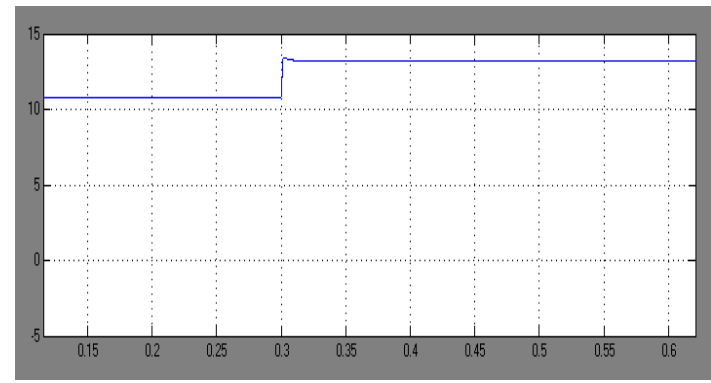

Fig.13Dc output voltage with disturbance

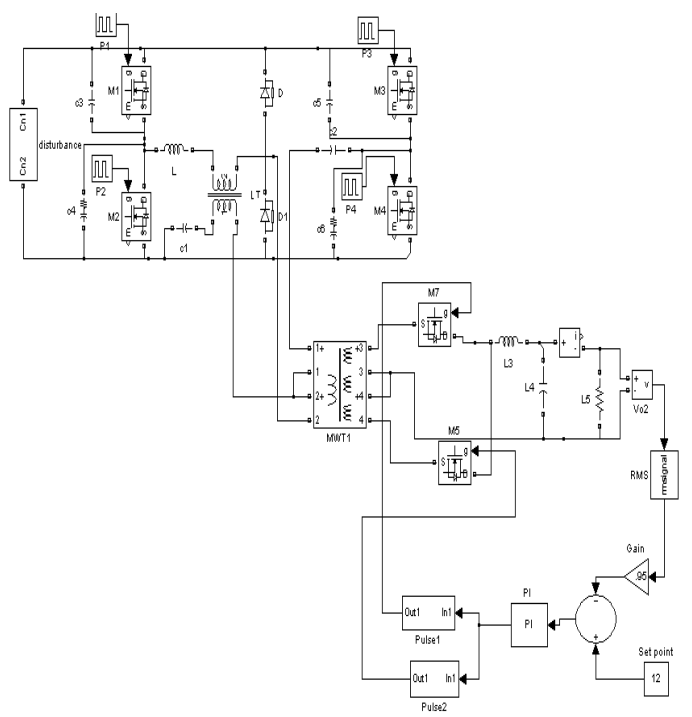

Fig.14 Closed loop system 


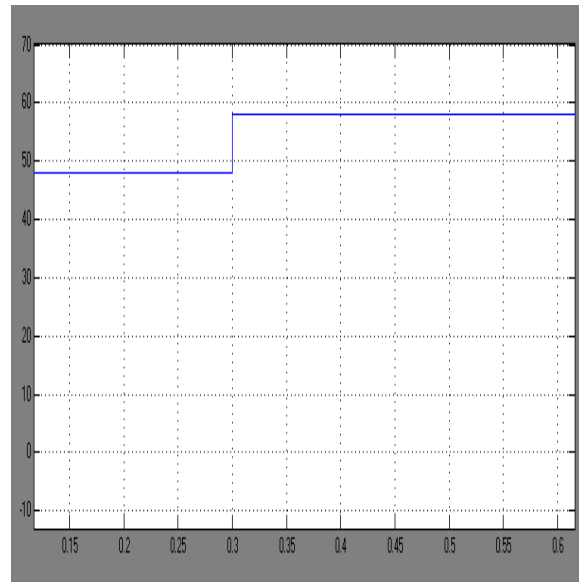

Fig.15 Dc input voltage with disturbance

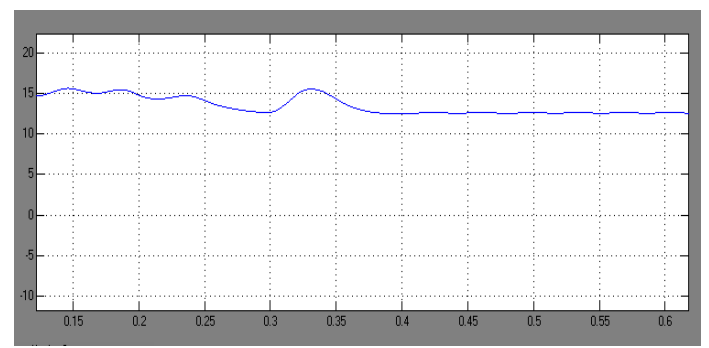

Fig.16 Dc output voltage with disturbance

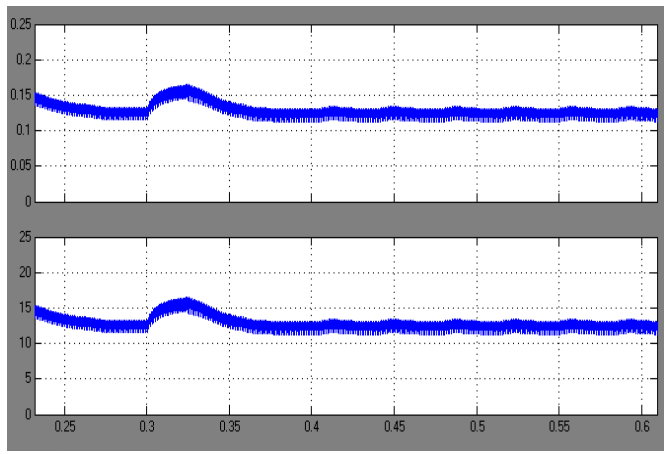

Fig.17 Output current and voltage with disturbance

\section{COMPARISON OF OPEN LOOP SYSTEM With CLOSED LOOP SYSTEM}

Simulink model of open loop system is shown in Fig.11 where input is given with disturbance. Fig. 12 shows the DC input voltage with disturbance. Fig.13 shows DC output voltage with disturbance. When input voltage changes due to disturbance in Fig.12, output voltage also changes.

Simulink model of closed loop system is shown in Fig.14. It consists of a feedback circuit. The R.M.S value of instantaneous voltage signal is taken from the output. To reduce the output, a gain of 0.95 is taken and given to the subtractor. Other input to the subtractor is the set voltage of $12 \mathrm{~V}$. Output of subtractor is the error signal which is given to the PI controller. The output of PI controller is given to the two comparators whose outputs are PWM waves. They are fed to the gates of MOSFETs $5 \& 7$ as control signals. The Fig. 15 shows DC input voltage with disturbance and Fig.16 shows DC output voltage with disturbance where output voltage changes with input. But the output reduces to a value of $12 \mathrm{~V}$. Output current and voltage with disturbance are shown in Fig.17.Thus the closed loop system is able to maintain constant voltage.

\section{CONCLUSION}

ZVS DC to DC converter is modeled using the blocks of simulink. Soft switched ZVS PWM DC to DC Converter is analysed and simulated and results are presented. Conversion from $48 \mathrm{~V} \mathrm{DC}$ to $12 \mathrm{~V} \mathrm{DC}$ is done using soft switched PWM converter. Switching losses and stresses are reduced using zero voltage switching. The simulation results are similar to the predicted results. This converter can be used for battery charging and Electrolysis. The scope of this work is the modeling and simulation of ZVS DC to DC converter. Hardware implementation is yet to be done. The simulation results are in line with the predictions.

\section{REFERENCES}

[1] R. Redl, N. O. Sokal, and L. Balogh, "A novel soft- switching full bridge dc-dc converter: analysis, design considerations, at $1.5 \mathrm{~kW}, 100$ kHz," IEEE Trans. Power Electron., vol. 6, no. 4, pp. 408- 418,Jul. 1991

[2] J. A. Sabaté, V. Vlatkovic', R. B. Ridley, and F. C. Lee, "High-voltage, high- power, ZVS, full- bridge PWM converter employing an active snubber," in Proc. IEEE APEC'91, 991, pp. 158163.

[3] W. Chen, F. C. Lee, M. M. Jovanovic', and J. A. Sabaté, "A comparative study of a class of full bridge zero-voltage- switched PWM converters," in Proc. IEEE APEC'95, 1995, pp. 893-899.

[4] P. K. Jain, W. Kang, H. Soin, and Y. Xi, "Analysis and design considerations of a load and line independent zero voltage switching full bridge DC/DC converter topology," IEEE Trans. Power Electron., vol.17, no. 5, pp. 649-657, Sep. 2002.

[5] R. Ayyanar and N. Mohan, "Novel soft-switching DC-DC converter with full ZVS- range and reduced filter requirement - Part I: Regulated output applications," IEEE Trans. Power Electron., vol. 16, no. 2, pp.184-192,

Mar. 2001

[6] A. J. Mason and P. K. Jain, "New phase shift modulated ZVS fullbridge $\mathrm{DC} / \mathrm{DC}$ converter with minimized auxiliary current for medium power fuel cell application," in Proc. IEEE Power Electron. Spec. Conf (PESC), 2005, pp. 244-249.

[7] Y. Jang and M. M. Jovanovic', "A new family of full- bridge ZVS converters," IEEE Trans. Power Electron., vol. 19, no. 3, pp. 701-708, May 2004.

[8] Mangesh Borage,Sunil Tiwari,Shubhendu Bharadwaj,and Swarna Kotaiah, "A Full-Bridge DC-DC Converter with Zero-Voltage -Swiching over the Entire Conversion Range," IEEE Tras.Power Electron,vol.23,No.4,July 2008.

[9] Martin Pavlovsky,Sjoerd Walter Hero de Haan , and Jan Abraham Ferreira," Reaching High Power Density in Multikilowatt DC-DC Converter With Galvanic Isolation," IEEE Trans. Power Electron., vol. 24, no. 3, March 2009.

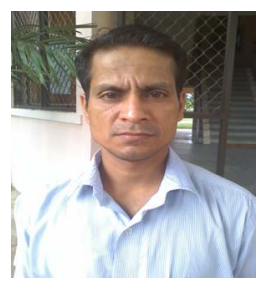

Deepak Kumar Nayak has obtained his degree A.M.I.E in Electronics and communication Engineering from Institution of Engineers (India) in the year 2002 and M.E in applied electronics from Anna University in the year 2005.He is presently a research scholar at Jerusalem College of Engineering centre for collaborative Research Anna University. He is working in the area of DC to DC converters. He is a member of IACSIT. 


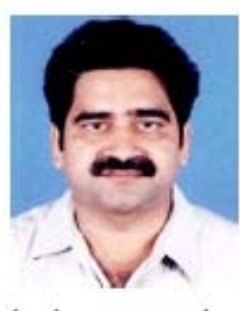

S. Rama Reddy is professor Electrical Department, Jerusalem College of Engineering, chennai. He obtained his L.E.E from S.M.V.M Polytechnic, Tanuku, A.P, A.M.I.E in Electrical Engineering from Institution of Engineers (India),M.E in power systems from Anna University, Madras and Ph.D in the area of power electronics from Anna University. $\mathrm{He}$ has published over 20 technical papers in national and international conference proceedings/ Journals. He has secured A.M.I.E institution gold medal for obtaining highest marks. He has secured AIMO best project award. He has worked in Tata Consulting Engineers, Bangalore and Anna University, Madras. He has teaching experience of 18 Years. His research interest is in the areas of resonant converters and solid state drivers. He is life member of Institution of Engineers (India), India society for technical education, system society of India and society of power Engineers. He is a fellow of institution of Electronics and Telecommunication Engineers (India). He has published text books on power Electronics and Solid state circuits. 